\title{
Exertional intolerance and dyspnea with preserved lung function: an emerging long COVID phenotype?
}

\author{
Grace Y. Lam ${ }^{1,2^{*}} \mathbb{D}$, A. Dean Befus ${ }^{1,2}$, Ronald W. Damant ${ }^{1,2}$, Giovanni Ferrara ${ }^{1,2}$, Desi P. Fuhr ${ }^{1}$, \\ Michael K. Stickland ${ }^{1,2}$, Rhea A. Varughese ${ }^{1,2}$, Eric Y. Wong ${ }^{1,2}$ and Maeve P. Smith ${ }^{1,2}$
}

\begin{abstract}
The COVID-19 pandemic has resulted in significant acute morbidity and mortality worldwide. There is now a growing recognition of the longer-term sequelae of this infection, termed "long COVID". However, little is known about this condition. Here, we describe a distinct phenotype seen in a subset of patients with long COVID who have reduced exercise tolerance as measured by the 6 min walk test. They are associated with significant exertional dyspnea, reduced health-related quality of life and poor functional status. However, surprisingly, they do not appear to have any major pulmonary function abnormalities or increased burden of neurologic, musculoskeletal or fatigue symptoms.
\end{abstract}

Keywords: Long COVID, Post-acute sequelae of COVID-19, Long-haulers

\section{Research Letter}

Coronavirus-19 (COVID-19) caused by severe acute respiratory syndrome coronavirus-2 (SARS-CoV-2) has rapidly spread across the globe, resulting in significant morbidity and mortality. While much focus has been paid to the acute phase of infection, there is a growing recognition of the longer-term sequelae of COVID-19, or "long COVID", defined by many as persistent post COVID-19 symptoms lasting beyond 12 weeks post infection [1]. While long COVID is thought to affect $10-50 \%$ of COVID-19 survivors [2, 3], little is known about who might develop these complications, which risk factors might predispose their development or how long they can persist.

Current literature suggests that patients with long COVID experience significant multi-system symptoms $[4,5]$. These complications have been reported in patients

\footnotetext{
*Correspondence: glam@ualberta.ca

1 Division of Pulmonary Medicine, Department of Medicine, University

of Alberta and Alberta Health Services, 3-111C Clinical Sciences Building,

1130283 Ave NW, Edmonton, AB T6G 2G3, Canada

Full list of author information is available at the end of the article
}

who had severe acute COVID-19 infections (requiring hospitalization) as well as those who had mild infections (not requiring hospitalization). In COVID-19 survivors of severe acute infections, the majority were found to have persistent fatigue, breathlessness or significant burden of psychological distress and reduced health-related quality of life at 1-2 months post discharge [6,7], while $63 \%$ still reported persistent fatigue or muscle weakness at 6 months' follow up [8]. Additionally, the 6-min walk test $(6 \mathrm{MWT})$, a simple but powerful tool that reflects exercise tolerance, was decreased in one-quarter of this cohort, independent of the care they received in hospital (routine hospitalization versus intensive care) [8]. This is a particularly striking finding given that the median age of patients in this study was 57 years.

To better understand this subset of patients with reduced exertional tolerance (defined as those with walk distance lower than their calculated lower limit of normal based on age, sex, weight and height) [9], we examined the first 165 patients seen in our Post COVID-19 Clinic in Alberta, Canada (June 2020-April 2021). Patients with persistent symptoms of at least 4 weeks in duration original author(s) and the source, provide a link to the Creative Commons licence, and indicate if changes were made. The images or other third party material in this article are included in the article's Creative Commons licence, unless indicated otherwise in a credit line to the material. If material is not included in the article's Creative Commons licence and your intended use is not permitted by statutory regulation or exceeds the permitted use, you will need to obtain permission directly from the copyright holder. To view a copy of this licence, visit http://creativecommons.org/licenses/by/4.0/. The Creative Commons Public Domain Dedication waiver (http://creativeco mmons.org/publicdomain/zero/1.0/) applies to the data made available in this article, unless otherwise stated in a credit line to the data. 
following acute COVID-19 are accepted for referral, regardless of the severity of their initial infection. The study was approved by the University of Alberta Research Ethics Board (Pro00104564) and conducted in full accordance with the ethics board guidelines. Statistical analyses were done with Prism 9.0 using non-parametric Mann-Whitney test unless otherwise specified.

The demographics (mean [standard deviation]) of these 165 patients are as follows: age 50.7[16]; body mass index (BMI) 30.7[7.4]; modified Medical Research Council (mMRC) dyspnea score 2.0[0.8]; health-related quality of life metric EQ-5D-5L 65[20.6] and days from first molecular test positivity $121.6[38.4]$. 66 of the 165 patients $(40 \%)$ required hospitalization during acute infection. 59 of the 165 patients (36\%) had a 6MWT distance less than the lower limit of normal (Fig. 1A). Of the patients who had reduced exertional tolerance: age 40.3[14.8]; BMI 28.9[6.9]; and days from molecular test positivity $112.0[65.4]$. Of the patients who had normal exertional tolerance: age 53.7[13.8]; BMI 30.7[7.4]; and days from molecular test positivity 136.5[68.4]. Unexpectedly, patients with reduced exertional tolerance were statistically younger $(40.3[14.8]$ versus $56.5[13.6] ; p<0.0001)$ and lighter (28.9[6.9] versus $31.7[7.6] ; p=0.02)$ than the patients with normal exertional tolerance. With regards to pre-existing comorbidities, patients with normal exertional tolerance had a significantly higher rate of previous or active smoking $(11 / 59$ vs $37 / 106 ; p=0.03)$ and hypertension ( $7 / 52$ vs $34 / 106 ; p=0.004)$ but otherwise no differences were found regarding rates of marijuana use or vaping, asthma, chronic obstructive pulmonary disease, coronary artery disease, congestive heart failure, diabetes, mental health disorders, musculoskeletal disease or peripheral vascular disease. No other statistically significant differences in baseline demographics between the two groups were noted. The rates of severe acute COVID-19 requiring hospitalization (35\% (20/59) versus $43 \%(46 / 106))$ and ICU admission (7\% (4/59) versus $16 \%$ $(17 / 106)$ were similar in both groups. With regards to treatment while in hospital, less patients received oxygen therapy $(20 \%(12 / 59)$ vs $41 \%(43 / 106) ; p=0.008)$ or dexamethasone $(20 \%(12 / 59)$ vs $41 \%(44 / 106) ; p=0.008)$ in those with reduced exertional tolerance than those with normal exertional tolerance. There were minimal use of remdesivir (0/59 vs $3 / 106)$ and hydroxychloroquin (0/59 vs $2 / 106$ ) in both groups. Assessment of patient reported mental health scores, those with reduced exertional tolerance reported a higher Patient Health Assessment-9 score (PHQ-9; validated questionnaire of depression) than those with normal exertional tolerance $(10[6.9]$ vs
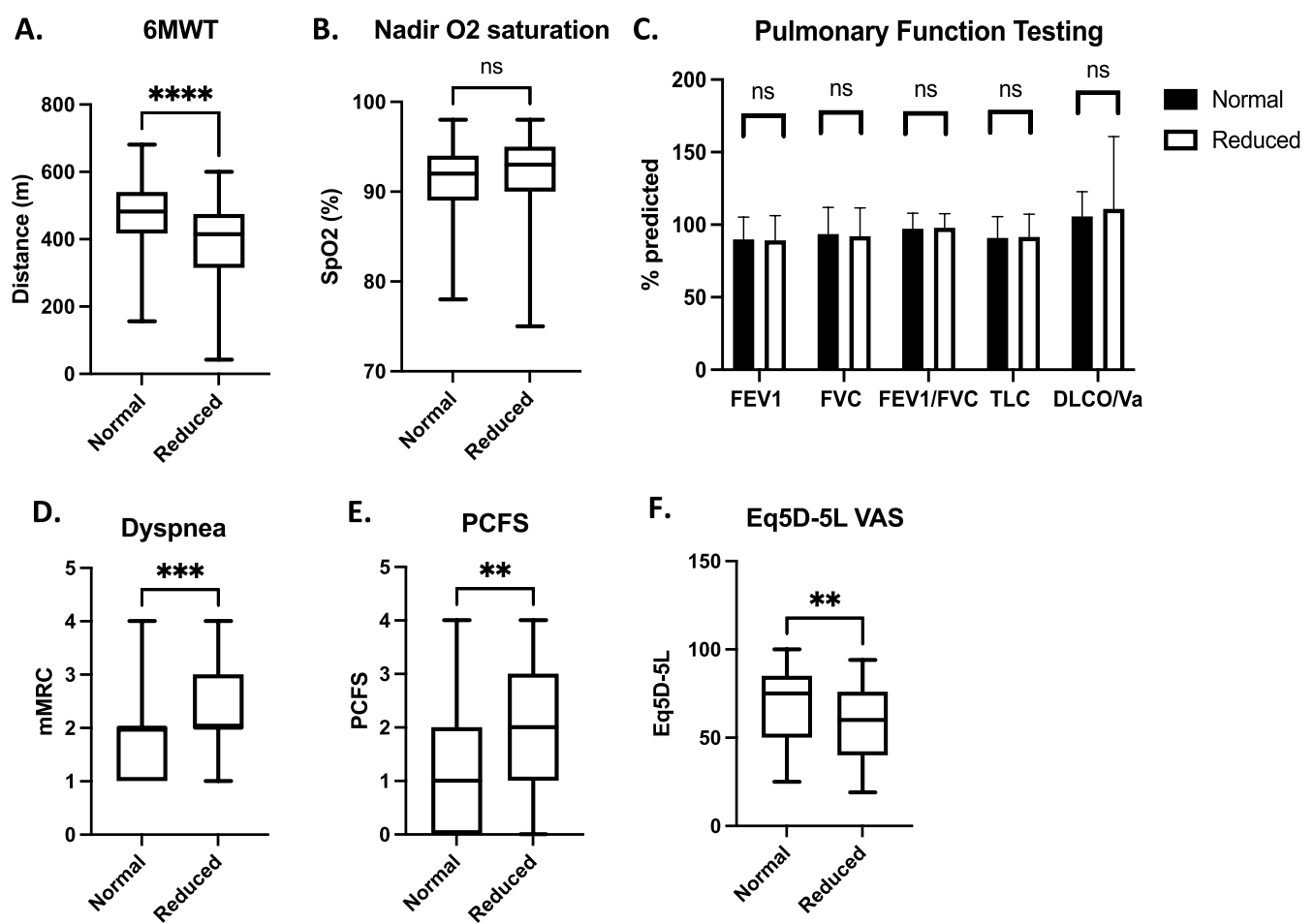

Fig. 1 Characterizing Patients with Long COVID who had Normal 6-min walk test (6MWT) Distances Versus Those who had Reduced Distances (Total $n=165$ ) by A 6MWT Distance; B Oxygen Saturation Nadir; C Pulmonary Function Testing; D Modified Medical Research Council (mMRC) Subjective Dyspnea Score; E Post-COVID Functional Scale (PCFS) score; $\mathbf{F}$ Health-related Quality of Life (EQ-5D-5L) score 
6.7[5.7]; $p=0.01$ ) but similar Generalized Anxiety Disorder-7 score (GAD-7; validated questionnaire of anxiety) in both groups (6.8[6.1] vs 5.3[5.5]; $p=0.2)$. 2 patients in the whole cohort (both with normal exertional tolerance) had attended or were attending rehabilitation or physiotherapy programs prior to being seen in the clinic.

The nadir oxygen saturation observed during the walk test was similar between those with normal versus reduced exertional tolerance (Fig. 1B). Overall, lung function on average was within expected normal limits and no differences in forced expiratory volume in one second $\left(\mathrm{FEV}_{1}\right)$, forced vital capacity (FVC), $\mathrm{FEV}_{1} / \mathrm{FVC}$, total lung capacity (TLC) or diffusion capacity adjusted for alveolar volume (DLCO/VA) between the two groups were noted (Fig. 1C). $\mathrm{Chi}^{2}$ analysis of symptoms demonstrated no differences between the two groups with regards to neurologic $(p=0.75)$, musculoskeletal $(p=0.14)$ or fatigue $(p=0.17)$ complaints. Interestingly, subjective mMRC dyspnea score was significantly higher for the reduced exertional tolerance group (Fig. 1D). These patients also reported more functional impairment, as reflected by a higher Post-COVID Functional Scale (PCFS) score (Fig. 1E), and a lower health-related quality of life (EQ5D-5L) score (Fig. 1F). 69\% of patients with normal exertional tolerance reported having returned to work at 3 months post-recovery compared to $62 \%$ of patients with reduced exertional tolerance $(p=0.53)$. Collectively, these observations suggest that the difference in walk distance is associated with significant subjective dyspnea and may have significant ramifications on overall function and quality of life but is unlikely to be due to a pulmonary limitation to exercise or confounding neurologic, musculoskeletal or fatigue symptoms.

From these findings, a distinct subset of patients with long COVID has emerged. These individuals may be younger, have marked reductions in exercise tolerance, are functionally limited and have significantly reduced health-related quality of life. Despite being, on average, 3-4 months from acute recovery, they have not yet returned to their previous functional baseline or level of health with a trend towards being less able to return to work. Even those with less severe acute disease not requiring hospitalization appear to be at risk. Given the burden of symptoms, impairment and potential for longterm disability, early identification of these individuals for targeted symptom management, intensive rehabilitation, characterization of disease trajectory and ongoing clinical research is warranted.

What is less clear is the underlying mechanism(s) of exertional limitation. These individuals do not appear to demonstrate pulmonary limitation to exercise, nor are they disproportionately symptomatic from a neurologic, musculoskeletal or fatigue perspective. This could be due to the lack of sensitivity in baseline clinical and pulmonary functional assessments. More sophisticated testing, such as cardiopulmonary exercise test (CPET), may be needed to better understand the cause of the exertional limitation. Alternatively, other factors, including cardiac or vascular dysfunction, mental health comorbidities, or persistent systemic inflammatory response may be contributing to the observed exertional intolerance and dyspnea. The difference in PHQ-9 score between the groups suggests that mental health symptoms might contribute to reduced exertional tolerance. Further cardiac, radiographic, biochemical and pathologic assessment of these individuals will be needed to determine the pathophysiology of exertional limitations in patients with long COVID.

Intriguingly, our finding that those with reduced exertional tolerance had less exposure to dexamethasone raises the possibility that perhaps acute treatment with steroids could help to reduce long COVID complications. Further work with larger numbers and regression analyses controlling for covariates will be required to conclude whether acute use of steroids can independently influence long COVID development.

Patients with long COVID appear to be a heterogeneous population potentially classifiable into distinct phenotypic subgroups. Our findings highlight the importance of the $6 \mathrm{MWT}$ as a low cost but critical tool for the identification of individuals with exertional intolerance and dyspnea despite normal lung function.

\section{Acknowledgements \\ Not applicable}

\section{Authors' contributions}

GYL was responsible for conceptualization, data acquisition, data analysis and manuscript writing; ADB \& MKS were responsible for manuscript editing and review; RWD, GFS, RAV and EYW were responsible for data acquisition, manuscript editing and review; DPF was responsible for data acquisition and aggregation, manuscript editing and review; and MPS was responsible for conceptualization, data acquisition, manuscript editing and review. All authors read and approved the final manuscript.

\section{Funding}

No funding.

\section{Availability of data and materials}

The datasets used and analysed during the current study are available from the corresponding author on reasonable request.

\section{Declarations}

Ethics approval and consent to participate

The study was approved by the University of Alberta Research Ethics Board (Pro00104564) and conducted in full accordance with the ethics board guidelines.

Consent for publications

Not applicable. 


\section{Competing interests}

The authors declare that they have no competing interests.

\section{Author details}

'Division of Pulmonary Medicine, Department of Medicine, University of Alberta and Alberta Health Services, 3-111C Clinical Sciences Building, 1130283 Ave NW, Edmonton, AB T6G 2G3, Canada. ${ }^{2}$ Alberta Respiratory Centre, University of Alberta, Edmonton, AB, Canada.

Received: 21 May 2021 Accepted: 26 July 2021

Published online: 06 August 2021

\section{References}

1. Greenhalgh T, Knight M, A'Court C, Buxton M, Husain L. Management of post-acute covid-19 in primary care. BMJ. 2020. https://doi.org/10.1136/ bmi.m3026.

2. COVID symptom study. How long does COVID-19 last? https://covid19. joinzoe.com/post/covid-long-term?fbclid=|wAR1RxlcmmdL-EFjh_al. Updated 2020. Accessed 27 Feb, 2021.

3. Trinkmann $F$, Muller M, Reif $A$, et al. Residual symptoms and lower lung function in patients recovering from SARS-CoV-2 infection. Eur Respir J. 2021. https://doi.org/10.1183/13993003.03002-2020
4. Lopez-Leon S, Wegman-Ostrosky T, Perelman C, et al. More than 50 long-term effects of COVID-19: a systematic review and meta-analysis. medRxiv. 2021. https://doi.org/10.1101/2021.01.27.21250617.

5. Del Rio C, Collins LF, Malani P. Long-term health consequences of COVID19. JAMA. 2020. https://doi.org/10.1001/jama.2020.19719.

6. Halpin SJ, Mclvor C, Whyatt G, et al. Postdischarge symptoms and rehabilitation needs in survivors of COVID-19 infection: A cross-sectional evaluation. J Med Virol. 2021;93(2):1013-22..

7. Carfi A, Bernabei R, Landi F. Gemelli Against COVID-19 Post-Acute Care Study Group. Persistent symptoms in patients after acute COVID-19. JAMA. 2020;324(6):603-5. https://doi.org/10.1001/jama.2020.12603.

8. Huang C, Huang L, Wang Y, et al. 6-month consequences of COVID19 in patients discharged from hospital: A cohort study. Lancet. 2021:397(10270):220-32.

9. Enright $\mathrm{PL}$, Sherrill DL. Reference equations for the six-minute walk in healthy adults. Am J Respir Crit Care Med. 1998;158(5 Pt 1):1384-7.

\section{Publisher's Note}

Springer Nature remains neutral with regard to jurisdictional claims in published maps and institutional affiliations.
Ready to submit your research? Choose BMC and benefit from:

- fast, convenient online submission

- thorough peer review by experienced researchers in your field

- rapid publication on acceptance

- support for research data, including large and complex data types

- gold Open Access which fosters wider collaboration and increased citations

- maximum visibility for your research: over $100 \mathrm{M}$ website views per year

At $\mathrm{BMC}$, research is always in progress.

Learn more biomedcentral.com/submissions 